fied for a few hours-but no more-of the sort of measures that can be undertaken at home (paraldehyde intramuscularly in adequate dosage being a stand-by). But if status continues then admission to hospital should be arranged at once. When status occurs as the very first manifestation of epilepsy, as is not very uncommon when the causative focus is in the frontal region, the likelihood of an intractable form is much greater, and admission to hospital should certainly be arranged.

In established status the problem of management is threefold : to control the fits, to ensure an adequate airway and oxygenation, and to maintain the biochemical milieu interieur as normal as possible. Monitoring of fluid balance, electrolytes, blood urea, blood pressure, and pulse will be required, and a simple airway may be needed. If status is long continued then tracheostomy with full curarization and assisted respiration may be necessary; in that case monitoring of blood $\mathrm{PCO}_{2}$ and $\mathrm{PO}_{2}$ will also be called for. In some cases these measures are life-saving, and this makes the condition a matter for urgent admission to hospital.

The linchpin of treatment must remain the control of the fits, and the sooner this is achieved the less need there will be for other measures. If a substantial increase in routine anticonvulsants-given by injection rather than by mouthdoes not abolish fits and allow return of consciousness within an hour or two, additional drugs must be used. The remedy most widely advocated is paraldehyde given intramuscularly or intravenously in glucose saline or plasma drip. The wide margin between anticonvulsant and serious toxic doses makes this a drug of choice. Other preparations-soluble barbiturates, soluble phenytoin, and inhalation anaesthetics-have been successfully used, but have not in general displaced paraldehyde. Recently, however, a new drug diazepam (Valium), introduced initially as a muscle relaxant and tranquillizer, has been found to give benefit in status. First reports on it came from French neurologists. ${ }^{12}$ Now Drs. M. J. Parsonage and J. W. Norris in this issue of the B.M.F. (page 85) give their experience of its use in nine cases of severe status. They gave it intravenously and in seven patients attained immediate control of seizures. The effect was rapid and obvious both on clinical seizures and on electroencephalographic discharges. Although in seven cases other methods of treatment were also used-including paraldehyde in four-there was no doubt that diazepam was a valuable and at times decisive therapeutic agent. Its rapidity of action and its absence of serious toxic effects must recommend it as one first choice in the treatment of persisting status. Initially it should be given intravenously, and Parsonage and Norris advise a saline drip (100 mg. per 500 $\mathrm{ml}$.), though 10-mg. intravenous doses repeated may be given. Control may later be maintained by intramuscular injection. Once control is established a gradual return to the usual oral remedies should be undertaken. There is not yet any clear evidence that the drug is effective by mouth on its own, though it appears at times to be an effective adjuvant to others.

The addition of diazepam to the treatment of status does not reduce the seriousness of this condition. Parsonage and Norris's series contains two deaths, one patient with persisting severe dementia and one with residual hemiparesis. This morbidity is important and has been little considered heretofore. There is growing evidence that mental and neurological

\footnotetext{
' Naquet, R., Soulayrol, R., Dolce, G., Tassinari, C. A., Broughton, R., and Loeb, H., Electroenceph. clin. Neurophysiol., 1965, 18, 427.

- Gastaut, H., Naquet, R., Poire, R., and Tassinari, C. A., Epilepsia (Amst.), 1965, 6, $16 \%$.
}

deficit may follow status. This reinforces the argument for rapid control of the condition, for careful attention to the biochemical milieu while it lasts, and for early and if possible preventive treatment.

\section{Safer Dental Anaesthesia}

In July 1965 the Standing Medical and Dental Advisory Committees of the Central Health Services Council set up a Joint Subcommittee at the request of the Minister of Health with the following terms of reference:

To consider the use of general anaesthetics in general dental practice and to advise:

(1) How far the administration of general anaesthetics for conservative treatment can be justified, and

(2) How far the administration of general anaesthetics for any purpose without the attendance of a second practitioner can be justified.

This report has now been published ${ }^{1}$ and the members of the Joint Subcommittee must be congratulated on producing a document which not only will influence the future of dental anaesthesia but will also serve as a model of the way to present authoritative and exact information in a concise form.

The report classifies the main groups of patients whose clinical condition may justify general anaesthesia for conservative work in general dental practice as follows: (a) spastics or others who because of physical infirmity would be uncontrollable under local analgesia ; $(b)$ patients who are known to react adversely or to be resistant to local analgesics ; (c) mentally subnormal patients ; $(d)$ those whose psychological attitude to dentistry is such that they would refuse from fear any form of dental treatment not performed under anaesthesia and who, in the opinion of the dental surgeon, are unsuitable for local analgesia. It can be inferred from the report that the Joint Subcommittee thought some dental practitioners were making too little use of local analgesia for conservative dentistry, for the introduction of lignocaine as an analgesic agent nearly twenty years ago has made the employment of local analgesia reliable and certain. For many years the average Briton had an ingrained fear of the dental surgeon and did not consult him until he could request him to take all his teeth out "with gas but not cocaine." Little wonder then that he prefers that such conservative dentistry as he will permit should be performed while he is asleep. In other countries, such as the U.S.A. and Scandinavia, where local analgesia has been the routine form of pain relief for all types of dental surgery, the use of general anaesthesia for conservative dentistry has not been so enthusiastically championed as in Great Britain.

The report is careful to point out that the relatively low mortality connected with dental anaesthesia in the past is related to the short time for which it is administered. However, if longer operations become more frequent, the mortality and morbidity must inevitably rise, especially if practitioners who are not properly trained administer general anaesthetics for them. The report states that the "administration of general anaesthesia and the performance of dental surgery

\footnotetext{
'Dental Anaesthesia, Report of a Joint Subcommittee of the Standing Medical and Dental Advisory Committees on Dental Anaesthesia Medical and Dental Advisory Comm
Ministry of Health. 1967. H.M.S.O. ' Brit. med. Ұ., 1967, 1, 447.
} 
require the undivided attention of anaesthetist and operator respectively and ... cannot be combined without risk." This authoritative statement will surely receive general assent.

Indeed, when sending the report to hospitals the Ministry states in an accompanying circular, "When an anaesthetic for dental treatment is administered to a patient in hospital, it is important that there should be one person with a clearly defined responsibility for the patient's general condition and general health whilst in hospital." Clearly this implies that the anaesthetist is responsible both for the preoperative assessment of the patient and for immediate postoperative care and that this is a responsibility which cannot be delegated to the less skilled. There can be no doubt that when a patient is rendered unconscious for a considerable time it is in the interests of his safety for the same criteria to be followed even though the operative work is done as an outpatient either in hospital or in general practice. The report concedes that there would not be enough trained anaesthetists to make this possible in every case, but the section discussing undergraduate and postgraduate teaching of both medical and dental students is comprehensive and will give much food for thought to those concerned with this problem. In all, this report points the way to safer and better dental anaesthesia, some aspects of which were recently discussed in these columns, ${ }^{2}$ and it should encourage the development of this branch of the specialty of anaesthesia.

\section{A Year's Cancer Research}

The Forty-fourth Annual Report of the British Empire Cancer Campaign for Research was published this week. ${ }^{1}$ It is shorter than its immediate predecessors as a result of a decision to exclude accounts of incomplete or inconclusive work. The provision of author and subject indices is an improvement, though the latter is less valuable than the summary which introduced the report in previous years.

The first stage of cancer research is to define the problem, and this is the role both of cancer registries, such as those in Kampala, Jamaica, Fiji, and Neyyoor in South India, and of the special panels concerned with tumours of the testis, bone, and thymus. Some of the difficulties of this first stage are evident in the report from Neyyoor, where religious and health beliefs, shortages of pathologists, and language differences make it difficult to obtain a clear idea of the incidence of the disease. Nearer home epidemiological data are somewhat easier to obtain, and the calculation of death rates for cancers and other diseases for Scotland, Northern Ireland, and Eire will provide valuable basic information for future work. New tables produced by R. A. M. Case enable the calculation of the risk of cancer at particular sites during the period 1911-1960 in these countries.

Circumstantial evidence favouring a virus as the cause of Burkitt's lymphoma continues to accumulate, but direct proof remains elusive. Meanwhile a national survey of tumours of domestic animals in England has shown, as expected, a relatively high incidence of leukaemia in cattle, and efforts are being made to find a virus cause for both this disease and the lymphosarcoma of cats and dogs. Attempts to recover the mouse sarcoma virus from tumours induced by it in the hamster were unsuccessful, though Huebner and his colleagues are reported to have succeeded in doing so by growing the hamster tumour cells in vitro in the presence of a murine leukaemic virus. According to Professor M. G. P. Stoker the Kilham rat virus, an osteolytic virus isolated from transplanted tumours, is the first animal virus found to contain single-stranded D.N.A. An interesting observation is that the Friend virus depresses the immune response in mice; a similar effect has been observed in response to mouse thymic virus and to treatment with chemical carcinogens.

Under certain conditions immune reactivity may be enhanced by prior exposure to $x$-radiation. From Newcastle upon Tyne C. A. H. Trench, C. A. Green, and others report an increased response to sheep erythrocytes in both rabbits and rats irradiated two months earlier. This may be relevant to treatment of cancer by radiotherapy. In relation to causation, however, V. Wallis and P. C. Koller conclude that in mice there is no obvious relation between the level of immune responsiveness after radiation and the subsequent development of leukaemia.

A peculiar and apparently specific affinity between submesothelial tissues and asbestos is reported by F. J. C. Roe and his colleagues at the Institute of Cancer Research. This may explain the causal relationship between exposure to asbestos and mesothelioma. The relative risk of different types of asbestos remains uncertain, but it is of interest that $A$. and P. R. Peacock have seen malignant tumours in fowls at the site of injection of tremolite as well as of amosite and crocidolite. According to J. S. Harington and G. Macnab asbestos may be present in phagocytes both in phagosomes and free in the cytoplasm. In Belfast, where asbestos cancer occurs in relatively high incidence, the department of therapeutics of Queen's University organized a meeting of medical officers from the Northern Ireland Ministry of Health and Social Services, from the Medical Research Council, and from several large industrial firms, which resulted in a general agreement to abide by the "Code of Practice in Handling Asbestos" drawn up by the Asbestosis Research Council."

It is tragically true that many elegant and sometimes costly diagnostic techniques reveal cancers for which no more than palliative treatment is likely to be available. Of particular interest, however, is the localization of tumours by various isotope techniques. Like previous years, 1966 did not see the introduction of an automated system for the examination of cervical smears, but the development by A. I. Spriggs and $M$. M. Boddington of a technique for collecting and fixing cervical cells in suspension so that the cells can subsequently be stuck on to plastic tape for automatic scanning may be an important step forward. Similarly, the formation of a library of classified cervical cells should prove invaluable in the development of an automatic cell-recognition device. In view of the known association between poor sexual hygiene and the risk of cancer of the cervix uteri, it is perhaps surprising that more attention has not been paid to women attending venerealdisease clinics. In a survey of patients attending such a clinic H. C. McLaren and his colleagues in Birmingham found precancerous lesions in a number of women under 30 and in two under 20 years of age. Several groups of workers have persisted in their search for a suitable biochemical screening test for cervical precancer. In this connexion it is difficult

1 British Empire Cancer Campaign for Research, Annual Report for 1966, 1967. London.

2 Code of Practice in. Handling Asbestos, 1965. Internal Report drawn up by the Asbestosis Research Council.

3 Report of United States Veteran Administration Cooperative Urological Research Group, Surg. Gynec. Obstet., 1967, 124, 1011. 